\title{
Um grupo somente de meninas: nova experiência de Grupo Operativo no Projeto Amora
}

\author{
Giulia Rocha Giozza* \\ Nara Beatriz Kreling da Rosa
}

\begin{abstract}
Resumo: Este artigo traz o relato de uma atividade de grupo realizada no ano de $2012 \mathrm{com}$ doze meninas da $6^{\mathrm{a}}$ série do Colégio de Aplicação da UFRGS, coordenada pela orientadora educacional da série e sua monitora. $\mathrm{O}$ artigo apresenta a aplicabilidade da técnica do Grupo Operativo de Pichon-Rivière na escola com um grupo exclusivo do gênero feminino, que teve como tarefa explícita discutir questões próprias da idade. Os resultados evidenciaram que as pré-adolescentes aprenderam que a tarefa explícita proposta para o trabalho em equipe é facilitada quando são elaboradas entre os participantes suas ansiedades, fantasias, inseguranças e ações defensivas, ditas pelo autor como tarefas implícitas.
\end{abstract}

Palavras-chave: Grupo Operativo; Subjetividade feminina; Pré-adolescência; Ambiente escolar.

Abstract: This paper presents the report of a group activity carried out in 2012 with twelve girls from the 6th grade of the Colégio de Aplicação/UFRGS, which was coordinated by the grade Educational Advisor and her monitor. The paper shows the

\footnotetext{
* Estudante de Psicologia da UFRGS e monitora do NOPE - Núcleo de Orientação e Psicologia do Colégio de Aplicação da UFRGS. E-mail: giuliagiozza@terra.com.br

* Licenciada em Pedagogia: Habilitação em Orientação Educacional (UNISINOS); especialista em Aconselhamento Psicológico (UNISINOS); especialista em Psicodrama (UFCSPA); mestre em Letras (UniRitter). Orientadora Educacional do CAp/ UFRGS - Projeto Amora. E-mail: nara.rosa@ufrgs.br
} 
applicability of the Pichon-Rivière's Operative Group technique at school with a group exclusively of girls, whose explicit task was to discuss issues proper to their age. The results showed that the preadolescents have learned that the explicit task proposed for the teamwork is facilitated when participants' anxieties, fantasies, insecurities and defensive actions - said by the author as being implicit tasks - are elaborated between them.

Keywords: Operative Group; Female subjectivity; Preadolescence; School environment.

\section{Introdução}

A ideia de voltar a oferecer uma atividade de ensino no formato de Grupo Operativo no Projeto Amora surgiu da necessidade de um grupo de doze meninas que compunha a turma de $6^{a}$ série do Colégio de Aplicação da UFRGS. No ano de 2012, o Núcleo de Orientação e Psicologia (NOPE) contava com um número reduzido de profissionais para atender sua demanda. Os atendimentos individuais eram tão disputados que as próprias alunas tomavam a iniciativa de fazer agendamentos, a fim de dar conta do número de pedidos que não podiam ser atendidos no curto tempo do recreio escolar. A procura das meninas pelas profissionais do NOPE que atendiam a $6^{\mathrm{a}}$ série era justificada pelos mais variados motivos, desde conflitos no colégio até a busca por orientação em questôes pessoais, de relacionamento com colegas e com a família em geral. Ainda que os meninos também procurassem atendimento no Núcleo, em comparação com a procura das meninas, o número era mais reduzido e em situações mais pontuais, envolvendo conflitos em sala de aula com outros colegas ou desentendimentos durante atividades físicas e recreio. Esse fato pode ser justificado por questôes de gênero. Enquanto os conflitos entre as meninas são expressos por meio de linguagens verbais e não verbais, como comportamentos 
competitivos, olhares de desprezo, entre outros, os meninos fazem uso do corpo (mais especificamente de sua força física) para demonstrar relações de poder.

À medida que as meninas traziam suas queixas e anseios, fomos constatando que os motivos da procura individual por atendimento no NOPE giravam em torno das mesmas temáticas, quais sejam: a busca de um maior autoconhecimento, o enfrentamento de desafios frente às mudanças psicobiológicas e oscilações afetivas, a elaboração de fantasias sobre padrões de normalidade/ anormalidade e resoluções de conflitos entre elas. Todas essas temáticas tinham como fator predominante questões próprias do gênero feminino e da idade. Eram assuntos "de menina", que urgiam que fossem escutados. Ora, se as demandas individuais eram as mesmas, por que não atendê-las em grupo? Além de racionalizar economicamente o tempo, os resultados seriam bem mais imediatos e efetivos, uma vez que acreditamos nos efeitos do atendimento grupal. Assim sendo, após algumas conversas com os professores da série, conseguimos criar um espaço dentro da grade horária das aulas para que as alunas pudessem falar de seus anseios, seus conflitos, suas dúvidas e, assim, sentirem-se acolhidas e escutadas. Um espaço delas para elas.

Ao tomarmos a decisão de oferecer a atividade de grupo àquelas adolescentes, pinçamos alguns temas - que estavam relacionados com os que elas traziam individualmente ao NOPE - de forma a alcançar uma melhor organização e, ao mesmo tempo, propiciar uma experiência que iria além de um simples agrupamento de meninas: a de atuar em uma situação real de grupo, no campo grupal. Esse espaço se constituiria num momento de escuta na escola, planejado para o compartilhamento de dúvidas, conflitos e ansiedades das meninas, e que, na percepção delas, não acontecia em casa. É recorrente no discurso dos adolescentes ouvirmos que "minha mãe não me entende e minha mãe não me escuta, pois não tem tempo". Porém, ainda que conversassem sobre esses assuntos entre elas, as adolescentes demonstravam sentir falta da orientação de um adulto. 
É sabido que os adolescentes vivem numa constante ambivalência entre a busca de sua identidade individual e a necessidade de uma identidade grupal e social. Dessa forma, torna-se propício oferecer uma experiência que permita a vivência de atuar e desfrutar do campo grupal. A respeito da passagem da condição de agrupamento para a condição de grupo referida anteriormente, podemos dizer que ela consiste na transformação de "interesses comuns" para a de "interesses em comum". Nessa mesma direção, o psicanalista britânico Foulkes (1997) explica que o grupo se organiza como uma nova identidade, diferentemente da soma dos indivíduos.

As meninas que compõem o grupo focado neste artigo tinham entre onze e treze anos e, portanto, transitam entre a pré-adolescência e a adolescência propriamente dita. A adolescência é um período do desenvolvimento humano em que uma série de mudanças biológicas, psicológicas e culturais ocorre de forma mais acelerada e intensa. Isso faz com que a passagem por esse período de vida seja marcada por inseguranças, conflitos, ambivalências e ansiedades e é possível supor que muitas particularidades e idiossincrasias emerjam em decorrência dessas transformações. Winnicott (1990) explica que, nessa fase, ocorre "[...] um fortalecimento das defesas contra o fato de ser descoberto, isto é, ser encontrado antes de estar lá para ser encontrado". Por isso, "[...] os adolescentes formam agrupamentos mais do que grupos, e por parecerem iguais, enfatizam a solidão essencial de cada indivíduo". Os adolescentes aproximam-se dos iguais, cujos assuntos transitam como um círculo, carecendo da intervenção de alguém de fora que os compreenda, escute e oriente.

Entre as muitas razões que nos fazem acreditar na eficácia do trabalho com grupos, uma delas reside na visão que temos sobre o mundo em que vivemos - um mundo imediatista, cujas informações são passadas em flashes e desprovidas de uma reflexão mais cuidadosa. $\mathrm{O}$ tempo que as pessoas dispõem para escutar o outro segue nessa mesma direção. Na família ou na escola, espaços de interação por excelência, o mesmo fenômeno social acontece. As pessoas no mundo de hoje se encontram tão envolvidas em 
suas demandas pessoais que não dão conta de perceber a dimensão da necessidade dos outros; mesmo daqueles com os quais convivem mais proximamente. $\mathrm{Ou}$, ainda, as que se propõem a dar atenção, nem sempre o fazem da maneira como o outro gostaria de recebê-la ou necessita. Outro fator a ser considerado é o de que as situações de conflitos pessoais quase sempre pedem uma resposta instantânea, a qual, por conta desse imediatismo, dificilmente podem ser dadas no momento em que aparecem. Assim, a possibilidade de participar de um grupo que se depara com ansiedades em comum, orientado por especialistas nas quais confiam, surge para suprir essa carência.

\section{O Grupo, os objetivos e a estruturação}

Todo grupo, por si só, constitui-se numa necessidade básica de interação que assume o caráter de sustentação social e emocional, tendo em vista seu aspecto de identificação. De acordo com os autores da Psicologia Social, qualquer grupo é um agente terapêutico e todo grupo também o pode ser em relação a outro grupo. Os grupos operativos, em especial, não se configuram como um grupo de psicoterapia propriamente dito, embora costumem produzir, ao longo do seu processo, autênticos efeitos terapêuticos. A saber, considera-se como efeito terapêutico, neste contexto, qualquer tratamento, voluntário ou involuntário, dirigido a uma pessoa ou grupo, que traga um resultado benéfico. A respeito da aplicabilidade do grupo operativo, o psicoterapeuta Luiz Carlos Osório escreveu:

[...] as técnicas operativas são utilizadas em todas as situações em que o grupo possa converter-se numa unidade operativa centrada na tarefa - implícita e explícita - quer no trabalho institucional, na formação de profissionais, de líderes, com crianças, jovens e adultos (OSÓRIO, 1986).

O interesse em participar de uma experiência grupal geralmente acontece de forma espontânea, pelo fato de o ser humano 
ser essencialmente gregário. Todavia, grupos também podem ser formados artificialmente. Zimerman (1986) afirma que "[...] o que importa consignar, é que todo e qualquer grupo, quer tenha sido formado espontânea ou artificialmente, sempre estará sujeito a uma série de fenômenos psicológicos, tanto conscientes como inconscientes”. O Grupo das doze meninas teve algumas particularidades. A iniciativa emergiu por parte do desejo delas. Com isso, a demanda já surgira na origem da estruturação do Grupo. Em princípio, então, pode-se afirmar que o Grupo se formou espontaneamente, em virtude do grande interesse manifestado pelas alunas. Mas, ao mesmo tempo, também pode se considerar que o Grupo se formou artificialmente, uma vez que sofreu intervenção de alguém de fora do Grupo, a professora especialista e orientadora educacional da turma, que organizou o tempo e o espaço para que o Grupo ocorresse. Vale ressaltar que em nenhum momento houve manifestação de resistência por algum membro em participar do Grupo. Pelo contrário, a cobrança sobre o início do evento era frequente. $\mathrm{O}$ mesmo interesse foi mantido nos encontros seguintes.

Por outro lado, não seria possível o Grupo acontecer sem a presença da totalidade das alunas, uma vez que se tratava de uma atividade inserida no cotidiano escolar. Da mesma maneira, obedecendo a técnica do Grupo Operativo, os encontros não poderiam ocorrer sem a presença de um coordenador e de um observador. Para fazer as observações, o Grupo contou com a presença da aluna graduanda em Psicologia, que vinha realizando um trabalho junto ao NOPE e já tinha contato com a turma a qual pertenciam essas alunas. A atuação do observador em um grupo é muito importante para trocas posteriores com o coordenador, bem como para dividir as tarefas de registrar, coordenar e realizar as intervençôes pertinentes nas sessôes. A leitura feita pelo coordenador e pelo observador serve para atentar ao que perpassa a fala dos participantes, ou seja, o que está implícito. O horário determinado para os encontros ficou estabelecido de 
acordo com a grade horária semanal da turma de $6^{a}$ série, ocupando um tempo aproximado de 1 hora e 30 minutos.

As originais e mundialmente aceitas e praticadas contribuições de Enrique Pichon-Rivière, que fundamentam a teoria do Grupo Operativo, serviram para concretizar a proposta devido ao embasamento que o autor oferece quanto à compreensão do ser humano nas relações sociais. Seu referencial teórico tem sido um suporte fantástico para o estudo dos fenômenos que surgem no campo dos grupos, cuja finalidade não é psicoterápica, como já foi dito, mas sim a de operar numa determinada tarefa objetiva, de possíveis efeitos terápicos. A tarefa grupal pode ser de uma equipe de trabalho, de aprendizagem, de criação artística etc. Definimos, então, que a tarefa do Grupo seria de ensino-aprendizagem. A tarefa implica um fazer, que é refletir criticamente sobre esse próprio fazer e sobre as relações que vão se tecendo em função do objetivo que foi proposto pelo grupo. Essa reflexão é fundamental para, a partir dela, os obstáculos frente à mudança serem visualizados e resolvidos, para cuidar das ansiedades emergentes em relação à tarefa, assim como para a elaboração dos processos interacionais. A tarefa pode ser tanto implícita quanto explícita. Sob a tarefa explícita, manifesta, subjaz outra implícita, latente, constituindo duas dimensôes num mesmo processo. Na vivência grupal, as pessoas são articuladas por sua mútua representação interna, ou seja, a representação interna que cada um faz dos componentes do grupo. Como finalidade dessa vivência, temos a tarefa, que se propõe explícita e implicitamente. Em vista disso, e por já ter tido êxito em experiências anteriores junto aos alunos do Projeto Amoral, utilizamo-nos da técnica pichoniana para embasar teoricamente o Grupo.

A procura por uma sala apropriada para os encontros passou a ser um desafio dentro do espaço escolar. Deveria ser um lugar reservado, onde pudéssemos ter a garantia de que não

1. Artigo publicado em 1998 no Cadernos do Aplicação: ROSA, Nara Beatriz Kreling da. Grupo operativo: proposta de uma técnica que promove a escuta do aluno. Cadernos do Aplicação, Porto Alegre: v. 11, n. 2, p. 129, 1998. 
seríamos interrompidos e preferencialmente que não tivesse a interferência de muitos ruídos. Também foi importante não ser uma sala normalmente utilizada pelas alunas nas aulas, de forma a não se misturarem as diferentes atividades. Ainda que o Grupo ocorresse na escola, seus objetivos e sua dinâmica são bem diferentes das aulas. Da mesma forma, era preciso ser um ambiente acolhedor que transmitisse segurança, para que os participantes pudessem expor suas ideias e seus sentimentos, tal como o desafio de participar em grupo requer. As cadeiras foram organizadas em círculo. A propósito, o círculo é um delimitador de território, que simbolicamente representa quem está dentro e quem está fora, além de possibilitar a visibilidade de todos os membros. É imprescindível que todos consigam ver a todos. Além disso, analisar a topografia de um grupo, a maneira como seus participantes colocam-se nesse território, permite a percepção de um referencial de como anda o processo de relaçôes no grupo. Assim, inclusive os lugares que as meninas escolhiam para sentar foram registrados nos relatórios para posterior análise.

\section{Os encontros e o processo do Grupo}

No primeiro encontro, com a presença das doze meninas, foram feitas as combinações, os acordos iniciais, em suma, o contrato grupal. Regras normatizam as atividades. Portanto, respeitar regras de pontualidade e de frequência são importantes, para que as participantes acompanhem tudo o que se passa e para que não se sintam nem sejam excluídas. A garantia de que os encontros seriam sistemáticos foi fator condicionante para que o Grupo se efetivasse, assegurando, em conjunto com outros fatores, seu sucesso. Assim, essa garantia foi dada às meninas quando combinamos um mínimo de quatro encontros que, ao final, estenderam-se a nove sessôes. Rege a técnica que, no grupo, qualquer membro, inclusive quem o coordena, tem direito a trazer assuntos como tarefa grupal. Há um pré-requisito que 
talvez seja o mais significativo, que é o caráter de sigilo, visto que sentimentos e segredos de pessoas de dentro do grupo podem ser expostos, os quais certamente nenhum membro gostaria que fossem compartilhados com alguém de fora do grupo. Tudo o que se passa ali é de exclusividade daquele grupo e comungado dentro dele. Dessa forma, ficou combinado que não seria permitido conversar sobre o que acontecera no Grupo com ninguém de fora dele, nem manter conversas paralelas ou formar subgrupos durante a sessão. Foi explicado que a heterogeneidade dos membros é valorizada no sentido de que, por serem diferentes uns dos outros, os participantes podem estabelecer trocas e contribuir para o grupo com suas diferenças, aprendendo, ensinando e apoiando uns aos outros. As meninas acordaram que, havendo alguma situação que pudesse gerar desconfiança ou ruídos na comunicação, a coordenadora, ou mesmo algum membro, iria solicitar o compartilhamento com todos sobre o que estava acontecendo, viabilizando trabalhar a tarefa implícita. As regras num grupo, os limites estabelecidos para a convivência durante aquele período, serviram como elementos estruturantes. No grupo das meninas, surpreendentemente, as regras foram cumpridas assim que foram estabelecidas, desde a primeira sessão, como se as regras tivessem vindo ao encontro das ansiedades delas. É interessante destacar que uma situação inversa acontece na sala de aula, quando estão reunidos meninas e meninos. É nítida a necessidade mais forte entre os alunos desta turma de $6^{a}$ série de que sejam estabelecidas regras firmes e claras para um bom rendimento individual, bem como para o funcionamento da aula. Para eles, particularmente, mais do que para outras turmas que já passaram pelo Projeto Amora, as regras são estruturantes e servem de continente.

A cada encontro, os depoimentos iam sendo registrados e as falas serviam de subsídio para análise. No nosso primeiro e tão esperado encontro só de meninas, tendo em vista ser justamente o primeiro, a coordenadora propôs uma dinâmica para iniciar o Grupo. Os assuntos trazidos, ou seja, a tarefa grupal, 
relacionava-se com a procura individual das meninas, anterior à formação do Grupo. As sugestões de assuntos foram escritas em tiras de papel. O Grupo estabeleceu uma votação que elegeu, por sete votos de doze, que o assunto a ser tratado seria: "Menstruar pela primeira vez, como foi? O que senti? Cuidados e sugestões para quem ainda não menstruou" 2 .

Logo, uma aluna tomou a iniciativa de ser a primeira a falar, contando como foi sua experiência. Contou que menstruou aos onze anos e ficou com medo, chegando a chorar. Ao mesmo tempo, enquanto se dizia assustada, também ria, pois estava feliz - chegou a pensar que pudesse ter se cortado. Na ocasião, estava na casa do pai e a madrasta foi quem a ajudou. Quando o pai apareceu, ela sentiu vergonha, e ainda mais intensa quando o pai falou: "Essa é a minha moça". A mãe, quando soube, começou a chorar, pois queria estar junto à filha quando essa menstruasse. A menina expressou não gostar do que sentiu por causa das cólicas. Não quis pedir muitas explicações para a mãe, porque sentia vergonha e assim tentou colocar o absorvente sozinha, mas posteriormente sua mãe lhe deu algumas explicações. A aluna também disse ter ficado com vergonha quando a mãe perguntou ao médico sobre remédio para gravidez. A coordenadora, frente à fala da menina, fez então sua primeira intervenção perguntando se a menina sabia o porquê dessa pergunta feita pela mãe, ao que ela respondeu ter conhecimento do assunto, por se tratar de um tema já estudado em seu Projeto de Aprendizagem. Disse saber que as duas coisas estavam relacionadas - menstruação e gravidez. Enquanto falava, seus olhos lacrimejaram, demonstrando a relevância que o assunto tinha em sua vida, assim como a carga emocional que o envolvia. É inevitável que, com a formação de um campo grupal dinâmico, ocorram fantasias, ansiedades, mecanismos defensivos e funções resistenciais. A importância do

2 As outras opções de assuntos eram: "Como eu posso saber que um guri gosta de mim? Como se tem certeza de que se gosta de alguém? Vale à pena perder a amizade de uma amiga para ficar com um guri?"; "Por que certas pessoas ficam com tanta vontade de beijar ou ficar? Se os pais não deixam, o que fazer?" e "Minha família não me compreende. Como devo reagir?” 
assunto entre as meninas foi reafirmada quando duas meninas demonstraram saber o dia e o horário aproximado em que uma das colegas havia menstruado pela primeira vez.

Seguindo a ordem de inscriçôes, a segunda menina a falar contou que se surpreendeu com uma amiga que menstruou aos oito anos - "aquela pirralha" (sic) - enquanto ela, que já tinha "quase catorze anos", ainda não. Disse ter inveja de quem menstrua mais cedo, pois já "viraram mulher" antes dela. Informou que todas as mulheres de sua família (mãe, avó, irmã) menstruaram tardiamente. Também perguntou ao grupo quem ainda não havia menstruado, demonstrando sua preocupação em encontrar semelhantes e buscando se sentir integrada e pertencente ao grupo. Quando compartilham suas ansiedades com seus pares, elas se sentem mais facilmente compreendidas, pois passam por processos de desenvolvimento semelhantes e recebem apoio e ajuda. Seus sentimentos são externados pelas falas dos outros, tornando-se mais claros e menos intensos. O grupo "está" com elas naquilo que fazem e dizem. Na adolescência, especialmente, as meninas mostram-se "aliviadas" pelo simples fato de não serem as únicas a passarem por certas experiências ou viverem os mesmos conflitos, ou ainda terem as mesmas dúvidas e anseios, por isso a importância dessa troca e de saber por quais experiências cada uma já passou ou não.

Enquanto várias das meninas demonstravam ansiedade em relação à menarca ou queriam falar sobre como havia sido sua experiência, algumas demonstravam certo constrangimento quanto ao assunto e não queriam falar; outras, ainda, expondo sua opinião sobre o assunto, disseram não ter nenhuma pressa por menstruar, pois achavam "chato", tendo em vista que sabiam que trazia cólicas, que precisariam trocar de absorvente "a toda hora" e que as impediria de ir à praia. Uma das meninas demonstrou apreensão quanto à espera pela menarca, pois tinha medo de que acontecesse na escola, o que a faria sentir muita vergonha. Não ter pressa para menstruar ou ter vergonha revelam atitudes de resistência frente à mudança. Essas expressões resumem uma 
situação a ser avaliada por quem coordena um grupo, servindo como um exemplo de tarefa implícita.

Entre medos, dúvidas, vergonhas e angústias, as meninas se dividiam entre as que valorizavam mais o lado negativo da menstruação - como a cólica, o medo de saberem na escola que haviam menstruado, o desconforto quanto ao uso de absorventes e os sentimentos de nojo e vergonha - e as que valorizavam o lado positivo, pois a entendiam como um sinal de estarem amadurecendo e se tornando "mulheres".

Ao final, ainda no primeiro encontro, puderam-se observar no Grupo alguns indicativos de relação de ajuda. As diferenças pessoais das meninas entre os pequenos grupos formados antes da nossa intervenção foram amenizadas e elas puderam trocar experiências sobre a menarca (através das informações de quem já havia menstruado), sobre a ida ao ginecologista, sobre como colocar o "o.b.", sobre como lidar com os pais e outras dicas, além de compartilharem questôes em comum, sentindo-se acolhidas. Por parte das meninas, elas enfatizaram muito o fato de que gostariam de ter mais tempo para conversar sobre esse assunto. Algumas alunas também comentaram sobre o quanto foi significativo contar com a presença e o apoio esclarecedor da mãe neste novo momento de suas vidas.

No que tange à manifestação das participantes acerca de que o tempo que tinham para discutir e analisar suas questões pessoais era insuficiente, o Grupo foi em busca de uma solução para esse problema. A forma como o Grupo operou para solucionar a necessidade apontada, que aconteceu no terceiro encontro, foi a criação de um grupo privado na rede social Facebook, onde todas seriam adicionadas. O nome escolhido foi: "De Mulher para Mulher”. Assim, as meninas teriam um espaço também virtual para comentar o que fora discutido no Grupo, além de utilizar outros recursos, tais como imagens.

Como o uso do Facebook não é permitido para menores e alguns pais cautelosos não concordam com o acesso por parte de seus filhos, houve a preocupação de solicitar a autorização 
das famílias. Sendo assim, foi enviado um bilhete informando a criação do grupo virtual aos pais. Por ser privado, apenas quem fosse adicionado ao grupo poderia ler e comentar as postagens. Com isso, algumas mães também puderam acompanhar um pouco do que se passava no Grupo, desencadeando inclusive diálogo presencial em casa com suas filhas.

À medida que os encontros foram acontecendo, outros assuntos foram sendo tratados e um jogo de identificações foi surgindo, representando a comunicação, nas suas múltiplas formas de apresentação - verbais e não verbais, sendo esta última um aspecto de especial importância na dinâmica das relações pessoais e grupais. Aos poucos, o Grupo foi se mostrando coeso e bem constituído, exercendo uma importantíssima função de continente das angústias e necessidades de cada uma das meninas. Nos encontros seguintes, muitas temáticas foram analisadas, entre elas o porquê da curiosidade dos meninos em saber o que acontecia no grupo feminino e a rivalidade pelo sexo oposto manifestada pela oposição de algumas: "Não! Esse grupo é nosso! Não vamos falar sobre eles (os guris da turma)". Em contrapartida, também pôde ser observado o interesse pelos meninos - os mais velhos. Além disso, surgiram questões sobre como ajudar umas às outras, através de pedidos de apoio: "O que eu faço, então?" e orientaçôes sobre como reagir em determinadas situações. A exclusão, como estratégia para que colegas mudem seu comportamento de forma a se adequar ao grupo, também foi posta em questionamento. Todavia, em vários desses momentos, ficou evidente a emoção ao falar das amizades e o quanto elas sentem que isso é importante, da mesma forma que a adolescência foi vista como um período importante mas difícil, no qual se irritam fácil, sem compreenderem bem o porquê. A oportunidade do encontro do "eu" de um participante com o "eu" de outros se configura numa experiência de discriminar, afirmar e consolidar sua própria identidade.

A discussão sobre relacionamentos foi recorrente. Emergiram as diferentes formas de se relacionar com a família: "Com 
a minha mãe não dá pra falar - ela já chega atropelando”, por um lado, e "Minha mãe é minha melhor amiga" por outro; o relacionamento entre elas mesmas - "Tive a ideia de falar sobre amizade, pois tivemos várias brigas entre nós, meninas"; a vergonha na relação com os pais frente aos amigos; questionamentos sobre qual é seu papel na família; o ciúme em relação aos parentes mais novos e assim por diante. Da mesma maneira, a individualidade ficou evidente em alguns momentos, em que manifestavam: "Não quero falar, quero ouvir", "Quero ficar sozinha" e "Quero ter meus momentos de descanso, de dormir sem nenhuma interrupção".

Analisando os registros, pode-se acompanhar o processo grupal no que tange à flutuação de papéis no Grupo. A título de exemplo, é citada a situação em que um dos membros do Grupo costumava tomar a iniciativa das falas atraindo para si a atenção dos demais, assumindo, com isso, o papel de líder. À medida que o processo do Grupo foi evoluindo, o Grupo deixou de legitimar esse papel para a colega em exclusivo. Para a manutenção do seu status, a aluna investiu em expressar experiências que o grupo percebia como sendo fantasiosas, devido ao caráter exagerado das suas narrativas, caindo no descrédito dos seus pares. Para atenuar a sua ansiedade, a aluna, então, passou a agredir verbalmente alguns membros, interromper as falas e ainda, num último suspiro, sair da sala sem solicitar. O bloqueio de aprendizagem da colega foi percebido pelo grupo, tendo em vista a evolução processual já construída por alguns membros. De líder, passou a ser o "bode expiatório”. Segundo Pichon, essa flutuação de papéis é saudável no grupo. A troca de lugares também serviu como recurso de análise para avaliar a mudança de papéis no grupo.

Nos últimos encontros, por fim, o Grupo experimentou uma vivência emocional intensa - uma autêntica catarse. Um assunto difícil de ser falado, por ser doloroso, e que, até então, tinha sido apenas tangenciado. As meninas libertaram um forte sentimento - o sentimento de perda pela morte de pessoas queridas - guardado e até escondido de suas famílias por muito 
tempo por algumas delas. A dor das perdas pôde vir à tona e ser compartilhada quando as meninas sentiram que no grupo haveria continente para as suas tristezas. O assunto foi considerado como culminante e se deu no oitavo encontro. Todas choraram, por se identificarem com situações semelhantes, cujo fator desencadeante foi a iminência da perda/despedida de uma delas, já que mudaria de escola no final do ano. Isso se ampliou, então, para a revelação da dor pela perda de pessoas muito próximas. Nesse dia, todas puderam verbalizar suas perdas ainda não choradas, as quais eram permeadas por sentimentos de vazio, de saudades e de incompreensão. Soube-se mais tarde, pelo relato de mães, que algumas meninas conseguiram compartilhar em casa esse sofrimento, em depoimentos nos quais as mães se viram surpreendidas, uma vez que não tinham conhecimento da dimensão de sua importância para suas filhas. A partir desse forte momento de tristeza, surgiu por iniciativa delas a ideia de organizar uma confraternização com lanches e um amigo secreto. Dessa maneira, o último encontro ficaria marcado pela alegria e também pela troca: uma lembrança do Grupo e das colegas através do presente da amiga secreta. Uma comemoração pela rica experiência compartilhada.

\section{Considerações finais}

Ao criarmos um grupo só de meninas, pretendíamos mais do que promover a troca de experiências: queríamos oportunizar a discussão de temas próprios da idade e a cooperação entre as doze meninas daquela turma. Além de abordar o relacionamento entre elas, tínhamos a intenção de tocar no seu afetivo, tendo em vista o favorecimento de um desenvolvimento psíquico saudável e um olhar para si e seus pares - trazido por meio de relatos e problemas, ouvindo umas às outras. Assim, elas aprenderiam a sair do nível da queixa para a postura reflexiva, tornando-se mais 
críticas e autônomas quanto ao que acontece consigo e à sua volta, elaborando conflitos e tomando decisões mais assertivas.

Ao longo dos encontros, fomos tendo a certeza de que esses objetivos estavam sendo alcançados e que o trabalho de Grupo Operativo com essas alunas teve grandes resultados positivos, quer de aprendizagem, quer de amadurecimento. Por sinal, o amadurecimento foi logo percebido pelos próprios professores, que reconheceram a evolução do comportamento, não de uma, mas de todas as meninas em sala de aula. $\mathrm{O}$ mesmo entendimento foi expresso por uma aluna, que postou no grupo no Facebook um depoimento testemunhando que a experiência grupal transcendeu os momentos do próprio grupo:

[...] lembro que nas primeiras aulas, a gente parecia não confiar uma na outra, acho que essas aulas nos aproximaram muuuuiiiitooooo! poder contar segredos, conversar, pedir conselhos, dar conselhos... poder confiar nas outras gurias! eu notei, não sei se vcs notaram tbm, mas não é só no grupo que temos essa liberdade, em outras aulas, por exemplo nas aulas de ed. física, nos jogos, acho que estamos mais unidas digamos assim!

No Grupo, elas aprenderam a observar, a escutar, a relacionar as próprias opiniões com as das outras, a entender e aceitar que os outros podem pensar de modo diferente e a formular hipóteses de uma tarefa em equipe. Enfim, pode-se dizer que aprenderam a pensar e a "copensar". Da mesma forma, a consolidação de um único grande grupo de doze meninas foi resultante da aproximação dos pequenos grupos em que as meninas estavam divididas anteriormente (a princípio, por afinidade), permitindo que se conhecessem, confiassem e se sentissem mais à vontade para se expor umas às outras e entre todas. Embora as meninas já se conhecessem desde a primeira série escolar, essa nova forma de relação de confiança foi muito importante. Ela se deu pelo simples fato de elas se exporem, falarem de seus sentimentos e sobre o que pensam, adquirindo suporte emocional para tal. Para Pichon-Rivière, todo grupo se inicia com medo da mudança. Em vista disso, seus membros guardam uma certa distância, apenas 
afiliam-se ao grupo, não se incluindo totalmente nele. Afiliação é o primeiro momento da história do grupo. Aos poucos vai surgindo um sentimento de pertença, de sentir-se integrado e identificado com os acontecimentos e as vicissitudes do grupo.

Ainda que praticamente todas contribuíssem para o Grupo - seja contando experiências próprias ou tangenciando o assunto através das experiências de amigas, seja questionando o grupo ou tentando ajudar de alguma forma, deixando mais à vontade as mais tímidas para falarem de si - algumas meninas ficaram quietas, abrindo-se ao grupo mais no final, como esperado. As meninas que pouco falaram durante as sessões nem por isso foram pressionadas. Seus membros deram indicativos de entendimento e respeito acerca das diferenças individuais, dando tempo e espaço às mesmas. Embora esses silêncios fossem verbais, expressavam uma energia muito forte na forma de olhar e na postura. Eram expressões de linguagem interpsíquica. $\mathrm{O}$ abraço, o toque físico, a análise das expressões faciais, a troca de olhares, as tentativas de cochichos, a troca de presentes no último encontro, tudo foi entendido como um diálogo. Nesses momentos, coube ao coordenador e ao observador atentarem a tais expressões para intervir de forma mais assertiva e facilitadora da interpretação de sentimentos. As intervenções foram importantes na medida em que os assuntos e o que acontecia no Grupo eram trazidos ao campo do explícito, para que todos vivenciassem o sentimento de pertença por meio da cooperação, sem a desconfiança dentro do grupo. $\mathrm{O}$ exercício de diferentes habilidades possibilitou que seus membros passassem a ser co-operadores numa mesma direção, tendo como objetivo alcançar a realização da tarefa grupal, e consistindo, em última análise, num treinamento para trabalhar em equipe.

De alguma forma, a partir dessa corajosa experiência de participar de um grupo em que expuseram suas necessidades emocionais, cada uma, a seu modo e de acordo com seus diferentes graus de vivência, "aprendeu a aprender" e poderá partir em busca de soluções mais adequadas para seus conflitos interiores, 
confiando um pouco mais nas pessoas com as quais conviverem e na via do diálogo e do respeito, deixando de subestimar a capacidade que o outro tem para ajudar e compreender.

Apoiadas no resultado positivo desse trabalho com meninas, sugere-se que a mesma técnica também seja utilizada em outras escolas e também com meninos, no intuito de estimular o diálogo e a expressão de sentimentos. Ao abrir tal espaço na escola para que os alunos possam falar de si, de questóes que possam estar atrapalhando seu rendimento escolar e de conflitos entre eles, estamos oferecendo um espaço preventivo, evitando que aflorem outros problemas que talvez necessitem de uma abordagem mais especializada, a qual o ambiente escolar não tem condições de oferecer. Especificamente quanto a um grupo de meninos, quer desta turma ou dos meninos em geral, a necessidade do trabalho grupal justifica-se devido à construção social do gênero, pois a interferência cultural os força a abafar seus sentimentos, que de uma forma ou outra acabam tendo ecos em seu comportamento no meio escolar. Por fim, de nossa parte, como coordenadora e cocoordenadora/observadora, foi um prazer enriquecedor ter vivido essa experiência com as meninas e agradecemos a elas por isso, bem como pela autorização da publicação deste artigo.

\section{Referências}

FOULKES, Siegfried Heinrich. In: ZIMERMAN, David; OSORIO Luiz Carlos. Como trabalhamos com grupos. Porto Alegre: Artes Médicas, 1997.

OSÓRIO, Luiz Carlos e colaboradores. Grupoterapia hoje. Porto Alegre: Ed. Artes Médicas, 1986.

WINNICOTT, Donald. O ambiente e os processos de maturação. 3 ed. Porto Alegre: Artes Médicas, 1990. 
ZIMERMAN, David. Como trabalhamos com grupos. Grupos Espontâneos: as turmas e gangues de adolescentes. Porto Alegre: Artes Médicas, 1986.

ZIMERMAN, David; OSORIO, Luiz Carlos. Como trabalhamos com grupos. Porto Alegre: Artes Médicas, 1997. 